\title{
Identificación de unidades de paisaje en la planicie costera de Rio Grande do Sul, Brasil, a través de técnicas de teledetección
}

\author{
Fernando Comerlato Scottá ${ }^{1}$ fernando.scotta@ufrgs.br, Rafael Mastracusa de Oliveira ${ }^{1}$, \\ Ricardo Franchini ${ }^{1}$ y Ricardo Ayup Zouain ${ }^{2,3,4}$
}

\begin{abstract}
RESUMEN
El objetivo de este trabajo es identificar las unidades de paisaje que permitan comprender los procesos dominantes de la paleogeografía en la zona costera de Rio Grande. Se utilizaron dos imágenes LANDSAT 8, usando el sensor Operational Land Image (OLI). Se realizó la fusión de la banda pancromática (banda 8) con las bandas 3, 4 y 5, generándose una imagen de 15 metros de resolución espacial. Fue posible identificar y mapear las unidades de paisaje en la zona de Rio Grande. En el área de sedimentos marinos del Holoceno, se identificó la presencia de crestas de playa regresivas intercaladas con depósitos eólicos. Las áreas de bancos de arena son paleo-orientaciones de la costa durante el Holoceno. El proceso de fusión de imágenes (sensor OLI) que permite la generación de una imagen de 15 metros de resolución espacial fue esencial en los resultados y como una propuesta metodológica de trabajo, ya que facilita la interpretación de las unidades de paisaje.
\end{abstract}

Palabras clave: cartografía geomorfológica, cartografía geológica, Holoceno, Pleistoceno y fusión de imágenes.

\section{Identification landscape units in the coastal plain of Rio Grande do Sul, Brazil, using techniques of remote sensing}

\begin{abstract}
The aim of this work is to identify landscape units to understand the paleogeographic dominant processes in the coastal zone of Rio Grande. Two images of LANDSAT 8, Operational Land Imager sensor (OLI), were used for this study. The process of merging the panchromatic band (band 8) with bands 3, 4 and 5 was performed, generating an image of 15 meters spatial resolution. It was possible to identify and map landscape units in the area of Rio Grande. In the deposition area of Holocene marine sediments, four units of regressive beach ridges were identified interspersed with areas of aeolian deposits. The sandbanks beam areas are paleo-orientations shoreline during the Holocene. The process of merging images OLI sensor allowing the generation of an image of 15 meters spatial resolution was essential as a work methodological proposal, because facilitated the interpretation of the landscape units.
\end{abstract}

Keywords: geomorphological, mapping; geological, mapping; Holocene, Pleistocene, image fusion.

Recibido el 21 de mayo de 2014, aceptado el 29 de junio de 2014.

1 Laboratório de Modelagem de Bacias - LABMODEL, Universidade Federal do Rio Grande do Sul/UFRGS, Avenida Bento Gonçalves, 9500. Porto Alegre, RS, Brasil.

2 Departamento de Geodésia, Universidade Federal do Rio Grande do Sul/UFRGS.

3 Centro de Estudos de Geologia Costeira e Oceânica, CECO, Universidade Federal do Rio Grande do Sul/UFRGS.

4 Instituto de Geociências/IGEO, Universidade Federal do Rio Grande do Sul/UFRGS. 


\section{INTRODUCCIÓN}

La planicie costera de Rio Grande do Sul tiene aproximadamente $33.000 \mathrm{~km}^{2}$, siendo la más extensa llanura costera del territorio brasileño. La línea de costa actual tiene una dirección NE-SW y se extiende por una distancia de unos $620 \mathrm{~km}$, desde Torres por el Norte, hasta la desembocadura del Arroyo Chuy por el Sur (TOMAZELLI \& VILLWOCK 2000). Por lo tanto, la planicie costera de Rio Grande do Sul es un conjunto complejo de cuenca sedimentaria surgido durante el Cuaternario. Numerosos estudios en los últimos decenios han interpretado la formación de la planicie costera de Rio Grande do Sul, a través del análisis de los eventos de deposición de sedimentos (VILLWOCK, 1994, 1984; TOMAZELLI \& VILLWOCK 2000).

Mediante el análisis de la distribución de facies sedimentarias y los depósitos de la planicie costera, VILLWOCK (1984), VILLWOCK et al. (1986) y VILLWOCK \& TOMAZELLI (1995) definieron la unidad como sistemas complejos de conos aluviales y lagunas-barrera, antiguos ambientes costeros deposicionales que conservan registros de las variaciones eustáticas del nivel relativo medio del mar durante el Cuaternario.

AYUP-ZOUAIN et al. (2003) describieron las características de estos sistemas, como morfologías de tipo planicies de paleocanales, dunas en cordones paralelos $\mathrm{y}$ planicies lagunares, formas costeras antiguas y ya consolidadas en el interior de la planicie costera de Rio Grande do Sul.

TOMAZELLI et al. (2006) se refieren a las variaciones eustáticas del nivel del mar registradas y datadas en depósitos cuaternarios. A partir de ello es posible correlacionar los depósitos eólicos y de playas, de cuatro registros de la planicie costera de Rio Grande do Sul con los cuatro hechos más significativos de la transgresión y la regresión de la costa, que datan del Pleistoceno, tales como los tres sistemas de laguna y barrera I, II y III, con aproximadamente $400 \mathrm{ka}$, $325 \mathrm{ka}$ y 125 ka respectivamente, y el Holoceno, sistema laguna y barrera IV, de aproximadamente $7 \mathrm{ka}$.

En la costa sur, en Rio Grande (Fig. 1) es posible observar la formación de crestas de playa regresivas, cubiertos por depósitos eólicos. Estas marcas serían huellas dejadas por antiguas líneas de la playa desde el Holoceno (GODOLPHIM 1985; CLEROT et al., 2003).

El objetivo de este trabajo es identificar las unidades de paisaje para comprender los procesos dominantes de la paleogeografía en la zona costera de Rio Grande.

\section{MATERIAL Y MÉTODOS}

\section{Geomorfología del área de estudio}

Se llevó a cabo una revisión de la literatura de la zona en los temas relativos a geología y geomorfología costeras. La cartografía con esta información base fue provista por la COMPAÑÍA DE LOS RECURSOS DE LA INVESTIGACIÓN MINERAL (CPRM). GODOLPHIM (1985) sugiere la presencia de tres grandes unidades geológicas debidas a la sedimentación predominante: los sedimentos de lagunas del Holoceno, sedimentos marinos del Pleistoceno y sedimentos marinos del Holoceno (Fig. 2).

Los sedimentos lagunares del Holoceno son el resultado de la deposición de sedimentos producido por el Canal de São Gonçalo. En esta zona de la laguna se intercalan depósitos planos y depósitos de tipo pantanoso. Entre el canal de São Gonçalo y el Océano Atlántico, se observa la presencia de sedimentos marinos del Pleistoceno. Esta unidad se compone principalmente de los depósitos de llanura lagunar, con algunas zonas de depósitos de playa y eólicos. 


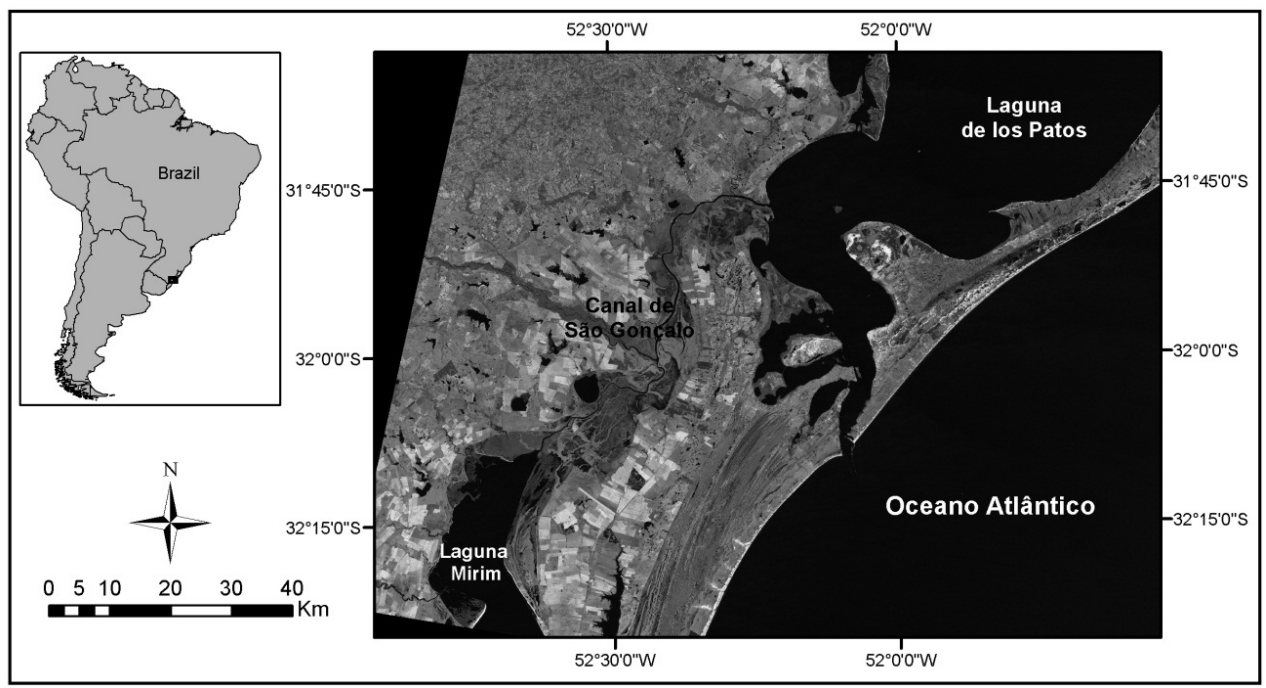

Fig. 1. Localización del área de estudio.

Fig. 1. Study area.

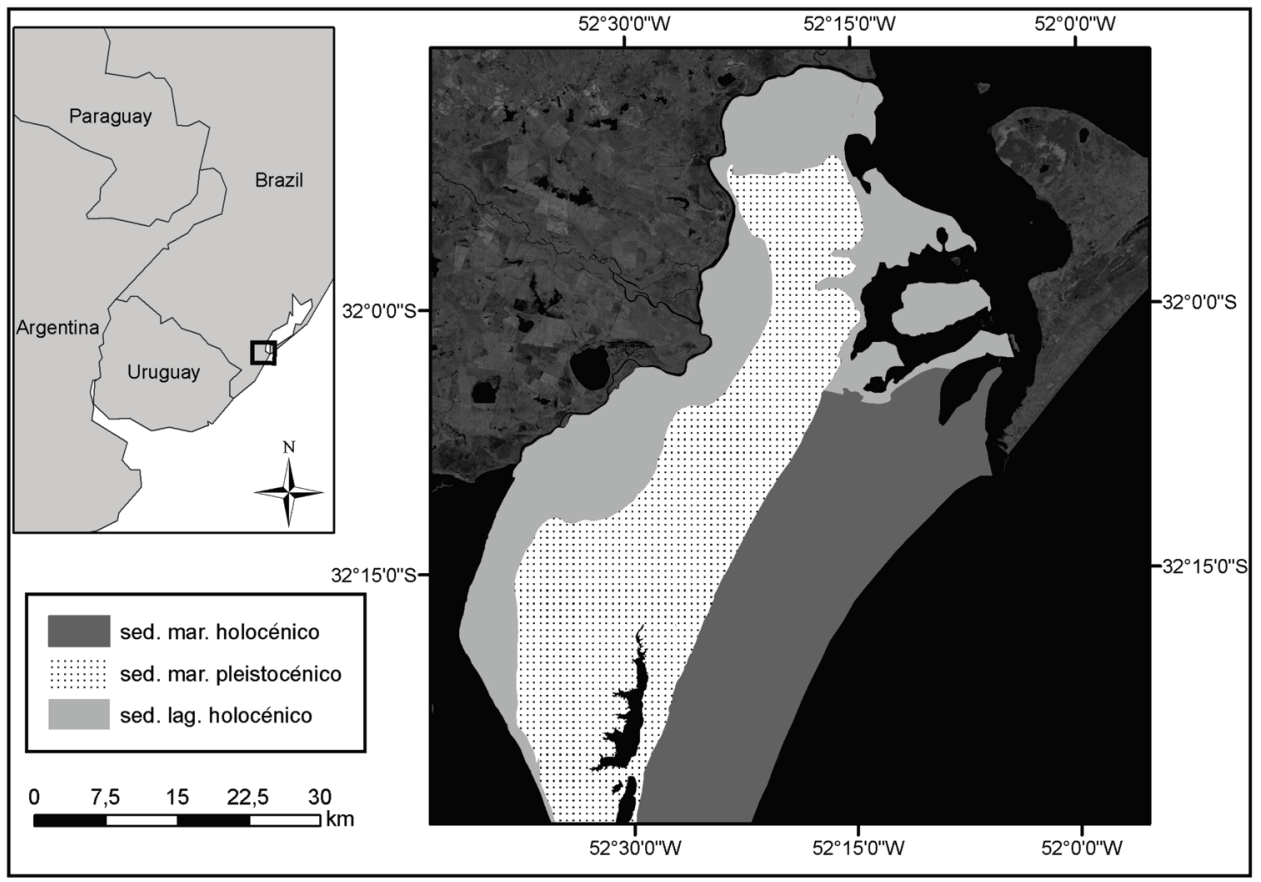

Fig. 2. Mapa de la geología de la zona.

Fig. 2. Geologyc map. 
La característica de los sedimentos marinos del Holoceno se encuentra al Este, limitando con el Océano Atlántico. Estas unidades están compuestas por crestas de playa regresivas y se intercalan entre estructuras de base en bancos de arena y depósitos eólicos reelaborados por el viento (GODOLPHIM 1985), más allá del campo de dunas en esta área.

\section{Análisis con teledetección}

Se utilizaron dos imágenes del LANDSAT 8, sensor Operacional Land Imager (OLI), para este estudio: la órbita 221, punto 082 y otro con la órbita 221, punto 083 , en la fecha de 21/01/2014 (Las imágenes fueron adquiridas a través el sitio http:// earthexplorer.usgs.gov/).

La elección del sensor de OLI está asociada a la posibilidad de aumentar la resolución espacial usando la banda mediante la fusión de imágenes. Por lo tanto, se realizó la fusión de banda pancromática (banda 8) con bandas 3,4 y 5 , con la generación de una imagen de $15 \mathrm{~m}$ de resolución espacial. Las imágenes adquiridas se registraron previamente en coordenadas Universal Transverse Mercator (UTM) Zona 22S. Las características geomorfológicas fueron interpretadas visualmente en aplicaciones ArcGIS. Se generaron dos mapas con la interpretación de unidades de paisaje en la zona: uno de los sistemas deposicionales y otra con mayor detalle en la zona de los sedimentos marinos del Holoceno.

\section{RESULTADOS Y DISCUSIÓN}

La asignación del nivel de unidades se observa en las figuras 2 y 3 . Cabe señalar que el nivel de unidades, que señala GODOLPHIM (1985), fue identificado en la imagen con el sensor OLI. En la unidad sedimentos lagunar del Holoceno no fue posible discriminar las áreas de la imagen de satélite del depósito de turba en la zona de la llanura lagunar.

La unidad de sedimentos marinos del Pleistoceno representa el área de formación de los sistemas de laguna y barrera II y III, con 325 ka y $125 \mathrm{ka}$, respectivamente. Se puede identificar los límites de las unidades geológicas por las diferencias de tono en la imagen. La unidad de sedimentos marinos del Pleistoceno se separaron de la unidad de sedimentos marinos holocénicos, como se muestra en la figura 2. Esta última unidad cuenta con depósitos más recientes, formando el sistema lagunar-barrera IV, construidos en el período Holoceno, con una edad de aproximadamente $7 \mathrm{ka}$.

En la figura 3, se identificó la presencia de crestas de playa regresivas de bancos de arena intercaladas con depósitos eólicos. Las estructuras de base en bancos de arena, mencionadas por GODOLPHIM (1985), se encuentran en zonas clasificadas como depósitos de playa en la planicie costera de Rio Grande do Sul.

La diferencia básica entre las dos unidades son los procesos de formación. Las áreas de bancos de arena corresponden a la formación de depósitos de playa, a diferencia de los depósitos eólicos, que se forman por la acción del viento. La formación produce diferencias en el tamaño de partículas. Las áreas de bancos de arena sólo tienen depósitos de arena fina, mientras que los depósitos eólicos tienen un tamaño medio de partícula.

Se identificaron cuatro unidades de crestas de playa regresivas de bancos de arena. El mismo resultado fue hallado por CLEROT et al. (2003). Según el autor, las crestas son representaciones de paleo-orientación de la línea de costa, evidenciando que la regresión marina ocurrió a través de pequeños pulsos. 


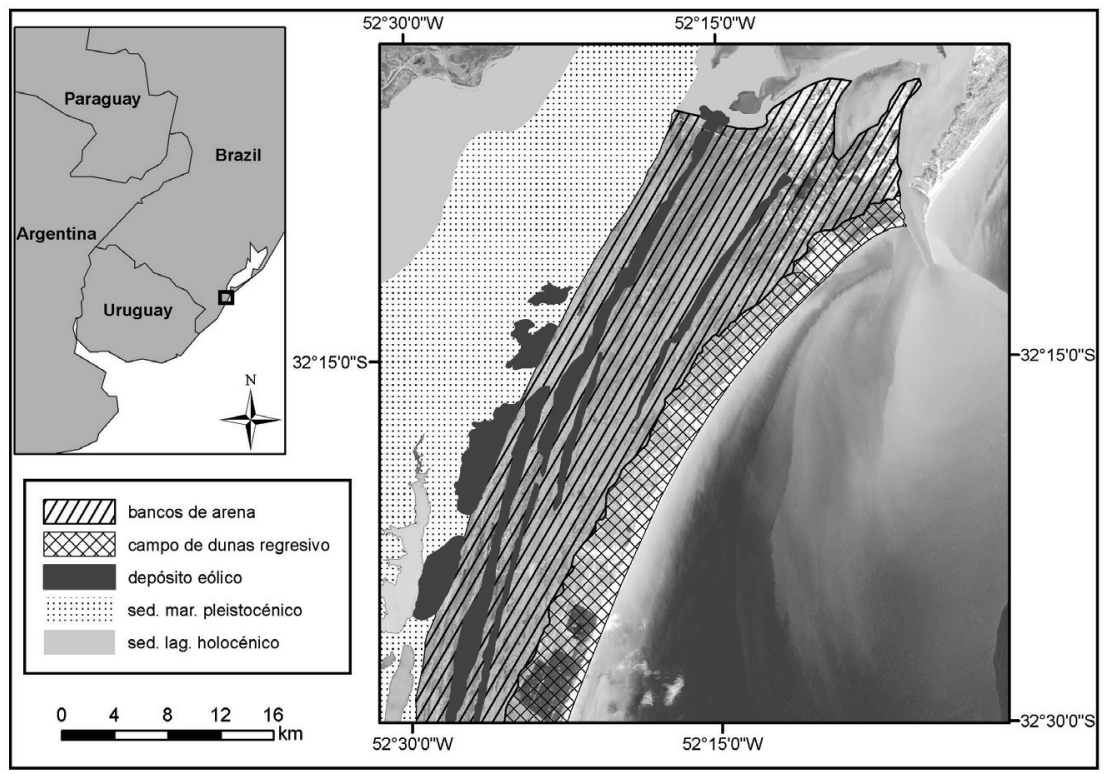

Fig. 3. Mapa de las crestas de playa regresivas de banco de arena, intercaladas con depósitos eólicos.

Fig. 3. Map of regressive beach ridges and sandbank intercalated with aeolian deposits.

\section{CONCLUSIONES}

Fue posible identificar y mapear las unidades de paisaje de la zona de Rio Grande. El proceso de fusión de imágenes del sensor OLI, que permite la generación de una imagen de 15 metros de resolución espacial, fue esencial como una propuesta metodológica de trabajo, ya que facilita la interpretación de las unidades de paisaje. La interpretación de unidades de paisaje costero, combinadas con estudios foto interpretativos previos, asociadas con eventos geomorfológicos observados en el campo y con las imágenes de satélite, permiten una mayor comprensión del proceso de construcción en la zona de Rio Grande.

\section{REFERENCIAS}

\section{AYUP-ZOUAIN, R.N., FERREIRA,} H.P.L., BARBOZA, E.G. \& L.J. TOMAZELLI, 2003. Evidência Morfológica de um Paleocanal Holocênico da Laguna Mirim nas Adjacências do Banhado Taim. In: Congresso da Associação Brasileira de Estudos do Quaternário, Recife: 5p.
CLEROT, L.C.P., MEDEANIC, S., TORGAN, L.C., DILlENBURG, S.R. \& J.L. TOMAZELLI, 2003. Evolução da Barreira IV na região do Cassino - RS. In: Congresso da Associação Brasileira de Estudos do Quaternário, Recife: 5p.

GODOLPHIM, M.F., 1985. Paleogeografia da Região do Cassino no Município de Rio Grande. Pesquisas, 17: 233-254.

TOMAZELLI, L.J., DILLENBURG, S.R. \& J.A. VILLWOCK, 2006. Geological Evolution of Rio Grande do Sul Coastal Plain, Southern Brazil. Journal of Coastal Research, 39: 275-278.

TOMAZELLI, L.J. \& J.A. VILLWOCK, 2000. O Cenozóico no Rio Grande do Sul: geologia da planície costeira. In: Holz, M., \& L.F. Ros. Geologia do Rio Grande do Sul. Porto Alegre: 375-406.

VILLWOCK, J.A., 1984. Geology of the Coastal Province of Rio Grande do Sul, Southern Brazil: a Synthesis. Revista Pesquisas, 16: 5-49. 
VILLWOCK, J.A., L.J. TOMAZELLI, VILLWOCK, J.A., 1994. A Costa E.L. LOSS, E.A. DEHNHARDT, Brasileira: Geologia e Evolução. Notas N.O. HORN, F.A. BACHL \& B.A. Técnicas, 7: 38-49.

DEHNHARDT, 1986. Geology of the Rio Grande do Sul Coastal Province. In: Quaternary of the South America and Antartic Peninsula, Rabassa, J. (ed.). A.A. Balkema, Rotterdam: 79-97.

VILLWOCK, J.A. \& L.J. TOMAZELLI, 1995. Geologia Costeira do Rio Grande do Sul. Notas Técnicas, 8: 1-45.

\section{Imagen de Investigaciones GEOGRÁFICAS}

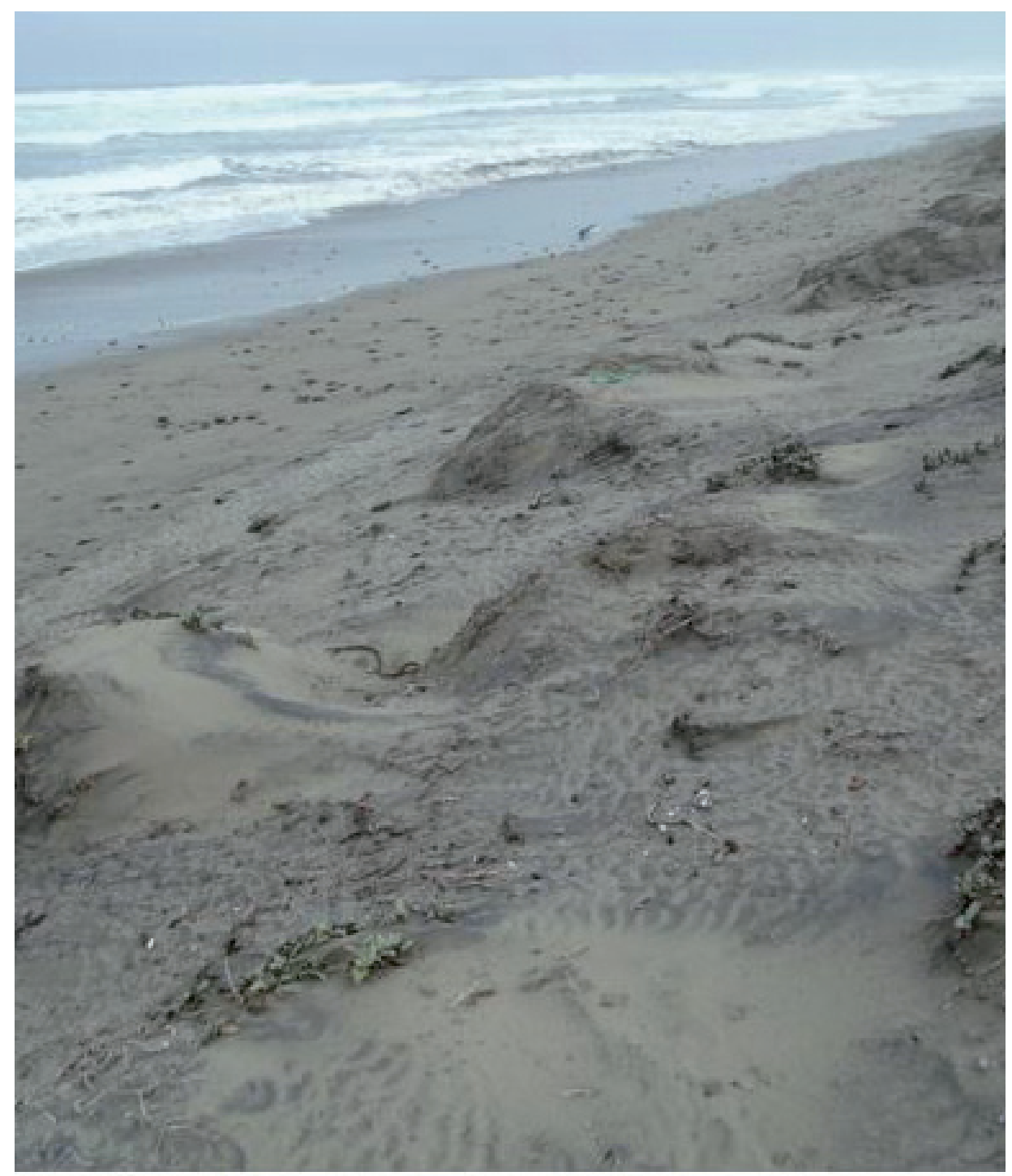

Dunas anteriores vegetadas erosionadas por el oleaje de una playa de tipo Disipativa. Campo de dunas Los Choros, Región de Coquimbo Chile. Agosto de 2013. Proyecto Fondecyt 1120234.

María-Victoria Soto. Departamento de Geografía, Universidad de Chile. mvsoto@uchilefau.cl. 